\title{
A control strategy for induction motors fed from single phase supply
}

\section{Søndergård, Lars Møller}

Published in:

Conference Proceedings of the IEEE International Symposium on Industrial Electronics

Link to article, DOI:

10.1109/ISIE.1993.268830

Publication date:

1993

Document Version

Publisher's PDF, also known as Version of record

Link back to DTU Orbit

Citation (APA):

Søndergård, L. M. (1993). A control strategy for induction motors fed from single phase supply. In Conference Proceedings of the IEEE International Symposium on Industrial Electronics (pp. 152-158). IEEE. https://doi.org/10.1109/ISIE.1993.268830

\section{General rights}

Copyright and moral rights for the publications made accessible in the public portal are retained by the authors and/or other copyright owners and it is a condition of accessing publications that users recognise and abide by the legal requirements associated with these rights.

- Users may download and print one copy of any publication from the public portal for the purpose of private study or research.

- You may not further distribute the material or use it for any profit-making activity or commercial gain

- You may freely distribute the URL identifying the publication in the public portal 


\title{
A Control Strategy for Induction Motors Feed from Single Phase Supply
}

\author{
M. Sc. E. E. Lars Sondergaard \\ The Technical University of Denmark \\ DK-2800, Lyngby Denmark
}

\begin{abstract}
It is often required that a three-phased asynchronous motor can run at variable speed, which makes it necessary to use a three-phase inverter driven from a DC-source. Today, most inverters are driven from the network using a simple diode bridge and an electrolytic capacitor. The problem with the simple diode bridge and the electrolytic capacitor is that current is only drawn for short periods, which gives rise to harmonic currents in the network. For small drive systems (motor+inverter), l.e. less than $15 \mathrm{~kW}$, a single phase network outlet is onten used. The paper describes a method whereby the problem with harmonic currents, when using a single phase network connection, can be solved.
\end{abstract}

\section{Booster as $A C-D C$ converter}

There are many types of AC-DC converters that use a sinusoidal network current, e.g. forward, boost, and a number of resonant converters. On some points, the booster has an advantage with respect to the other types:

1. There is no capacitor that the energy is required to pass through as would be the case for the cuk-converter.

2. Furthermore, the harmonic ripple current caused by the booster is triangular rather than square-wave as in the case of the flyback and the forward converters.

One of the drawbacks of the booster is that the output voltage $V c$ across the capacitor is always greater than the amplitude of the network voltage.

Two examples of how it is possible to realise the boost converter are shown in the following.

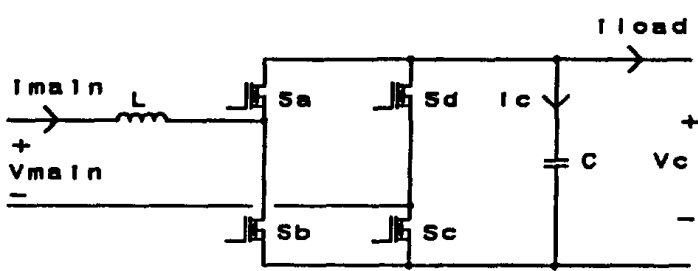

Fig. 1. A four-quadrant, single phase AC-DC boost converter.

0-7803-1227-9/93/\$3.00@ 1993 IEEE
The H-bridge looks like a simple diode bridge, but the diodes are exchanged with power switches. The network current is controlled by changing the voltage across the coil with the power switches. With an H-bridge it is possible to control the current, and therefore also the energy, in both directions, which is required in some applications with servo motors.

In many other applications it is not necessary to be able to send energy back to the network, and by eliminating this degree of freedom it is possible to reduce the number of switches from four to one.

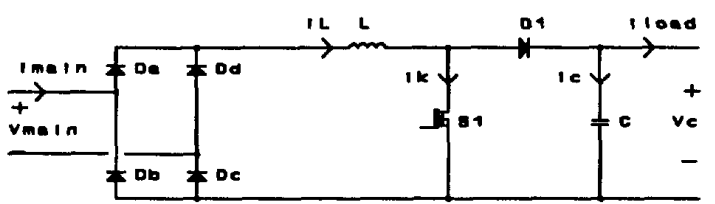

Fig. 2. A single quadrant, single phase AC-DC boost converter.

The most expensive components in the boost converter are the coil, the capacitor, and the switches, but with thick film technology it becomes less expensive to realise the switches.

With modern-day thick film technology it would be convenient to keep the capacitor voltage so low that MOSFET transistors can be used in both the booster and the inverter.

The size of the capacitor depends on the ripple in the capacitor current and on the energy that must be stored in the capacitor. When the switching frequency is high, and the line frequency is $50 \mathrm{~Hz}$, the $100 \mathrm{~Hz}$ component will dominate the capacitor current. This is due to the fact that a three phased asynchronous motor in stationary use absorbs constant energy. It is therefore the capacitor that supplies energy to the inverter, when the line voltage is less than a certain value, which happens twice in every network period. 


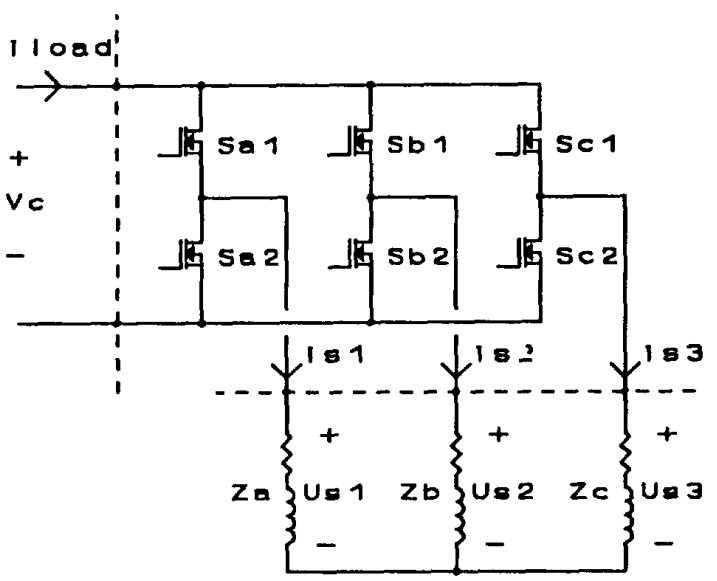

Fig. 3. A three phased VSI-inverter with a asynchronous motor as load.

If the line voltage Vmain is sinusoidal you find:

$$
\begin{aligned}
V_{\text {main }}(t) & =V_{0} \sin \left(w_{1} t\right) \\
I_{\text {main }}(t) & =I_{0} \sin \left(w_{1} t\right) \\
P_{\text {main }}(t) & =V_{0} I_{0} \sin ^{2}\left(w_{1} t\right) \\
& =\frac{P_{0}}{2}\left(1-\cos \left(2 w_{1} t\right)\right)
\end{aligned}
$$

where $V 0,10$, and $P O$, all are maksimum values.

The mean value of the power supplied from the network to the booster is:

$$
\left\langle P_{\text {main }}\right\rangle=\frac{P_{0}}{2}=\frac{V_{0} I_{0}}{2}
$$

Due to symmetry the power is only considered in the period:

$$
0<w_{1} t_{0}<\pi
$$

To examine the power flow in the capacitor the following is computed:

$$
\begin{aligned}
& \left\langle P_{\text {main }}>=P_{\text {main }}\left(t_{0}\right)\right. \\
& \Downarrow \\
& w_{1} t_{0}=\frac{\pi}{4} \wedge \quad w_{1} t_{0}=\frac{3 \pi}{4}
\end{aligned}
$$

If it is asumed that the capacitor is infinitely big it will absorb energy from the network when:

$$
\frac{\pi}{4}<w_{1} t_{0}<\frac{3 \pi}{4}
$$

and deliver energy to the inverter in the rest of the period.

This means that the capacitor must deliver energy to the inverter in $50 \%$ of the network period, which corresponds to $5 \mathrm{~ms}$, when the line frequency is $50 \mathrm{~Hz}$.

If it is possible to reduce the power consumption in the inverter when the line voltage is low, the size of the capacitor can be reduced significantly.

\section{Simulation of the booster}

The booster has been simulated on a PC using Matlab. In Figure $4 V c / V O=1.2$ and it is assumed that the inverter can be controlled so that Pmain = Pload. It is typical for a boost converter that the output voltage, which is equal to the capacitor voltage, is $20 \%$ higher than the maximum line voltage.

When Pmain = Pload the capacitor current is zero, and the output voltage is constant.

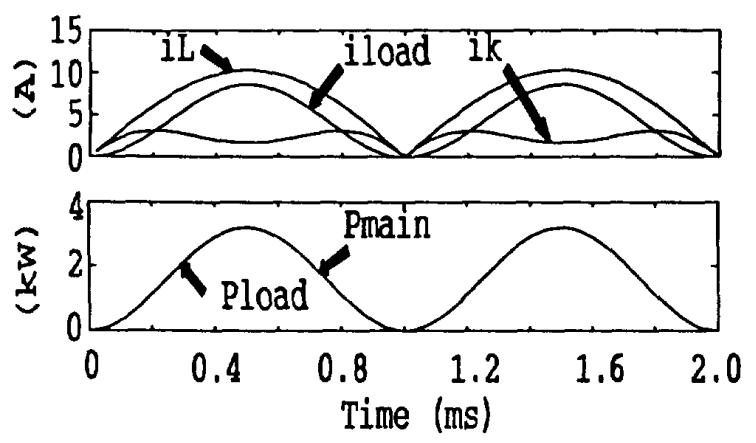

Fig. 4. The current and power patterns in a single phase boost converter.

The current in the switch $i k$ (See fig. 2) is only zero, when the line voltage is zero.

In the simulations the capacitor is set to $100 \mathrm{uF}$. The amplitude of the line voltage and the line current are set to $311 \mathrm{~V}$ and $10 \mathrm{~A}$ respectively, which gives a power output of $1.6 \mathrm{~kW}$.

Field vector control of the asynchronous motor to reduce $L$ and $C$ in the booster

The equations for the asynchronous motor in field vector coordinates are given by: where

$$
\begin{aligned}
& R s=\text { stator resistance } \\
& R r=\text { rotor resistance } \\
& L O=\text { the mutual inductance in the motor }
\end{aligned}
$$




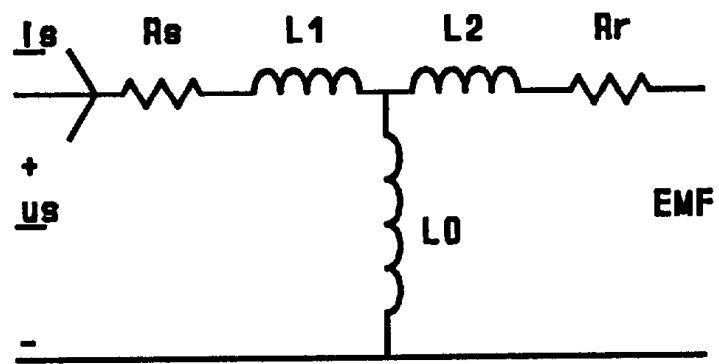

Fig. 5. The electrical diagram for the asynchronous motor.

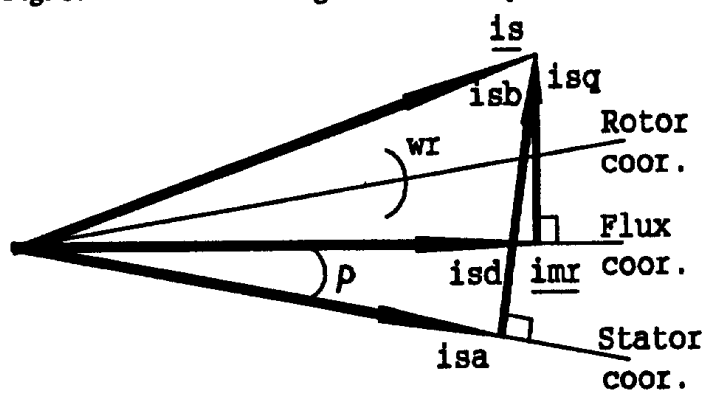

Fig. 6. Current vector diagram.

(1) $\quad d i_{m v} \int d t=\left(i_{s d}-i_{m v}\right) / T_{r}$

(2) $d \rho / d t=i_{s \phi} /\left(T_{r} i_{\text {mot }}\right)+p w_{r}$

(3) $i_{s d}=i_{s a} \cos (\rho)+i_{s b} \sin (\rho)$

(4) $i_{s q}=-i_{s a} \sin (\rho)+i_{s b} \cos (\rho)$

(5) $m_{d}=2 / 3 p L_{0}^{2} /\left(L_{0}+L_{2}\right) i_{m r} i_{s q}$

(6) $\quad d w_{p} / d t=\left(m_{d}-m_{l o a d}\right) / J$

$L I=$ the stray inductance in the stator $=L 2$

$L 2=$ the stray inductance in the rotor $=L I$

$p=$ number of pole-pairs in the machine

All these values are per phase, when the motor is coupled in a star-configuration.

Furthermore:

$T r=\quad$ rotor time constant $=(L 0+L 2) / R r$

rho $=$ angle between stator current phasor in stator and rotor flux coordinates

$i m r=\quad$ magnetising current $=$ magnitude of rotorflux divided by $L O$

isd = direct part of stator current phasor in rotor flux coordinates

$i s q=$ quadrature part of stator current in rotor flux coordinates

is $a=$ direct part of stator current phasor in stator coordinates

$i s b=$ quadrature part of stator current phasor in

$$
\begin{array}{ll}
m d= & \begin{array}{l}
\text { stator coordinates } \\
\text { the electrical moment } \\
w r=
\end{array} \quad \text { rotational speed }
\end{array}
$$

It is thus possible to control the rotor flux size/length and position with the stator current phasor. Normally, when field vector control is used in practice, you have maximum field on the machine, which is the same as keeping the length of the rotor flux phasor constant.

It may be seen that the size of the rotor flux is a lowpass filtering of the current isd, where the time constant equals the rotor time constant, which is the mutual inductance divided by the rotor resistance.

As the efficiency of an asynchronous motor depends on the air gap, motors are normally made with a small air gap, making the mutual inductance and the rotor time constant large. If isd is changed quickly there will be no influence on imr.

In formula 5 the moment is expressed as the motor constant times imr and isq. This means that when isq is constant, the moment will be constant even if isd is changed. By utilising the magnetising inductance and the rotor resistance it has become possible to manipulate the stator current without changing the moment.

The above description corresponds to keeping the stator flux phasor in the Q-direction constant and changing it in the Ddirection. The stator flux phasor thus performs a suitably fast movement in parallel with the rotor flux phasor.

\section{A practical relisation of the algorithm}

As described in section before the mean value of isd is equal to imr, as the rotor circuit acts as a lowpass filter.

The control strategy entails splitting it into a moment control and a flux control. Using a sampling, you must first:

1. Measure $w r$, isl and is2

and next

2. compute isa, isd, isq, md, and imr.

Moment control:

3. The moment regulator computes $m d^{\text {ref }}$ using $w r^{m t}$ and $w r$, whereafter 
4. $i s q^{\text {ref }}=1 /\left(2 / 3 p L 0^{2} /(L O+L 2) i m r\right] m d^{\text {ret }}$ is computed.

Flux control:

5. The flux regulator computes isd ${ }^{\text {ef }}$.

The difficult part in this control strategy is finding isdet, which is done by finding the power consumed by the motor. This can be done using the stator voltages, which either can be measured or computed.

In field vector coordinates the phasor for the stator voltages usd and usq are given by:

$$
\begin{aligned}
\frac{u_{s}}{t} & =u_{s d}+j * u_{s q} \\
u_{s d} & =2 L_{1}\left(L_{0}+L_{1} / 2\right) /\left(L_{0}+L_{1}\right) d i_{s d} / d t \\
& +R i_{s d}+L_{0}^{2} /\left(L_{0}+L_{1}\right) d i_{m} / d t \\
& -2 L_{1}\left(L_{0}+L_{1} / 2\right) /\left(L_{0}+L_{1}\right) i_{s q} d \rho / d t \\
u_{s q} & =2 L_{1}\left(L_{0}+L_{1} / 2\right) /\left(L_{0}+L_{1}\right) d i_{s d} / d t \\
& +R i_{s q}+L_{0}^{2} /\left(L_{0}+L_{1}\right) i_{m r} d \rho / d t \\
& +2 L_{1}\left(L_{0}+L_{1} / 2\right) /\left(L_{0}+L_{1}\right) i_{s d} d \rho / d t
\end{aligned}
$$

and the power is computed as:

$$
\begin{aligned}
& P_{\text {load }}(t)=2 / 3 u_{s}(t) \bullet i_{s}(t)= \\
& 2 / 3\left(u_{s d}(t) i_{s d}(t)+u_{s q}(t) i_{s q}(t)\right)
\end{aligned}
$$

The inverter is considered without losses, so that Pload is equal to the power that the AC-DC converter must deliver to the inverter and the motor. To reduce the size of $C$, isd must be chosen so that Pload equals Pmain.

An estimate of disq is the difference between is $q^{\text {ref }}$ and isq, and in the quasi-stationary mode, which corresponds to the intended application of this control method, disq/dt becomes zero.

The mean value of isd must be equal to imr (according to formula (1)), and isd $d^{\text {ref }}$ is chosen as:

$$
i_{s d}^{r e f}=i_{m r}^{r e f}+\sum_{k=1}^{N} I_{s d \ell} \cos \left(k w_{1} t+\phi_{k}\right)
$$

None of the cosine parts contribute to the mean value of $i s d$, and the reason for choosing ist thf as succession of cosine functions is that disd/dt and dimr/dt can be computed exactly.

The exact expressions for disd/dt and dimr/dt are:

As the control is digital, $t=n^{*} T$, where $T$ is the sampling

$$
\begin{aligned}
& d i_{\Downarrow} / d t=-w_{1} \sum_{k=1}^{W} k J_{s d, k} \sin \left(k w_{1} t+\phi_{k}\right) \\
& d i_{m} \int d t=-w_{1} \sum_{k=1}^{w} k I_{s d, k} \sin \left(k w_{1} t+\phi_{k}\right) \\
& +T_{r} w_{1}^{2} \sum_{k=1}^{W} I_{s d, k} \frac{k^{2}}{1+\left(k T_{r} w_{1}\right)^{2}} \\
& \text { - } \cos \left(k w_{1} t+\phi_{k}\right)
\end{aligned}
$$

period. By using an LMS (least Mean Square) algorithm, the values are found for $I s d, k$ and $\phi k$ that give the smallest error between $P$ main and $P l o a d$, as well as having $<P$ main $>$ equal to $<$ Ploads.

As isd $d^{\text {ret }}, i s q^{\text {ref }}$, and rho are known, you may compute $i s a^{\text {ref }}$ and $i s b^{\text {ref }}$, and these values are then carried to the current control that controls the phase currents:

$$
\begin{aligned}
& i_{s 1}=i_{s 1}^{\text {nof }}=2 / 3 i_{s a}^{\text {nof }} \\
& i_{s 2}=i_{s 2}^{\text {nff }}=1 / \sqrt{3} i_{s b}^{\text {nf }}-1 / 3 i_{s c}^{\text {nf }} \\
& i_{s 3}=-i_{s 1}-i_{s 2}=-i_{s 1}^{\text {nff }}-i_{s 2}^{\text {nof }} \\
& i_{s 1}+i_{s 2}+i_{s 3}=0
\end{aligned}
$$

Simulation of control algorithm for the motor

The simulations and measurements are performed on an ASEA motor and inverter with the following data:

$$
\begin{aligned}
& R s=0.88 \mathrm{Ohm} \\
& R r=0.84 \mathrm{Ohm} \\
& L O=0.122 \mathrm{H} \\
& L 1=5.27 \mathrm{mH} \\
& L 2=5.27 \mathrm{mH}
\end{aligned}
$$

and

$V c=\operatorname{sqrt}(2) 220 \mathrm{~V} 1.2=373 \mathrm{~V}$

is $1, \max =i s 2, \max =i s 3, \max =20 \mathrm{~A}$

which gives a rotor time constant $\operatorname{Tr}$ of $152 \mathrm{~ms}$. 
On Figures 7 through 13 are shown the patterns of power, currents, voltages and moments, when the motor is controlled in the standard manner with isd kept constant.

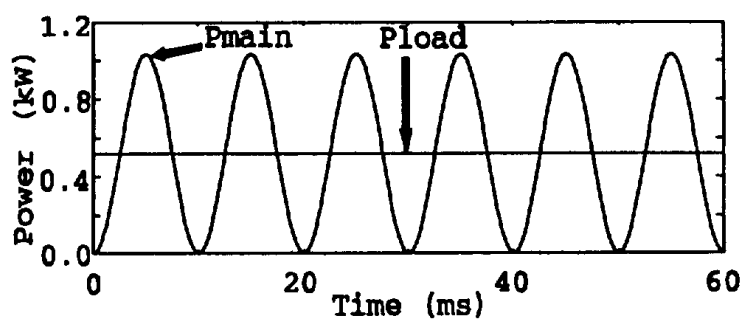

Fig. 7. The main power Pmain and the load power Pload.

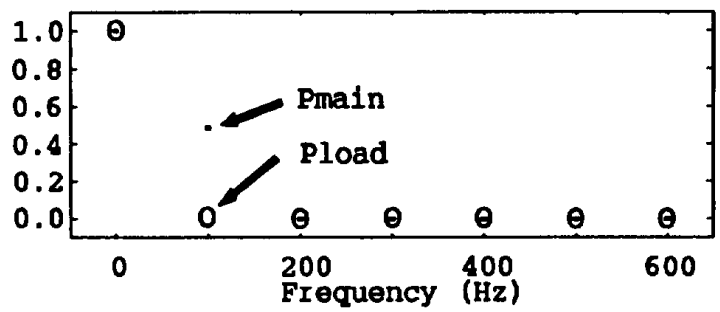

Fig. 8. The spectrum for main power Pmain and the load power Pload.

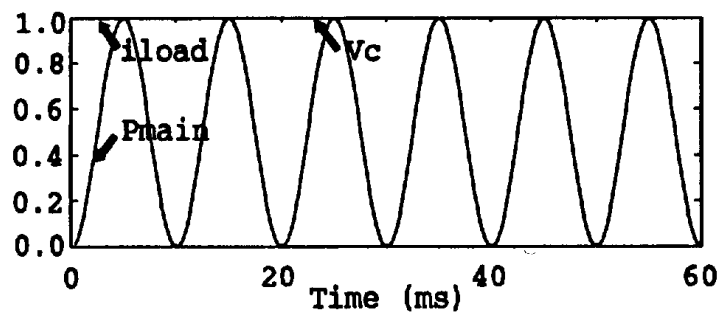

Fig. 9. The normalize value of the capacitor voltage $V c$ and the load current iload and the main power Pmain.

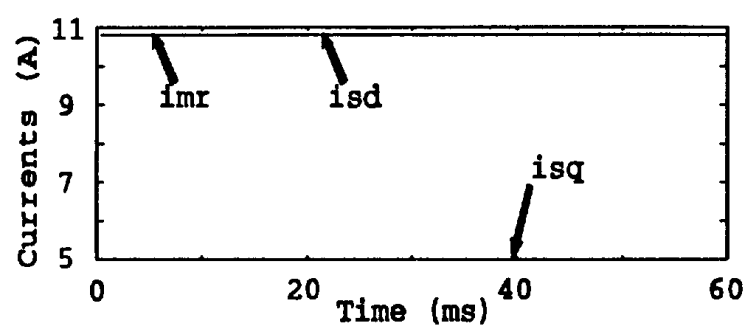

Fig. 10. The magnetization current $i m r$ and the stator current isd and is $q$ in field vector coordinates.

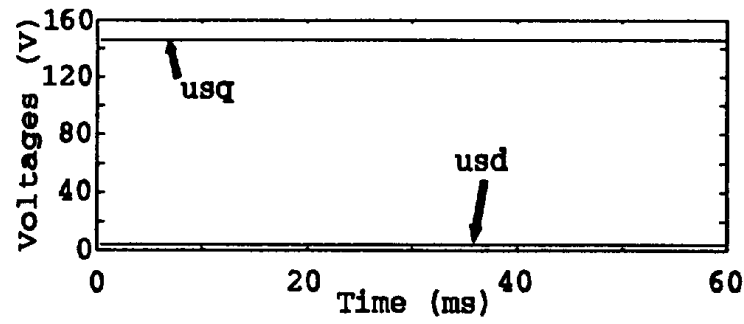

Fig. 11. The stator voltages $u s d$ and $u s q$ in field vector coordinates.

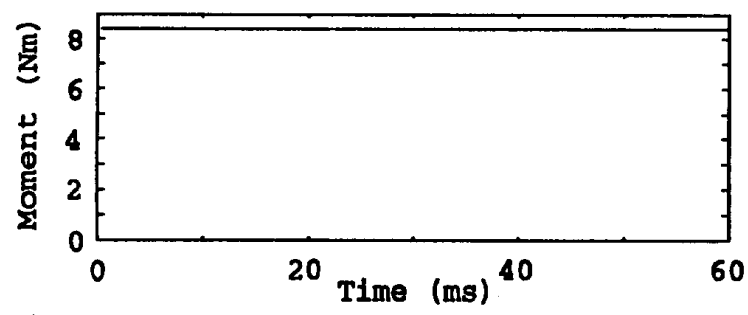

Fig. 12. The electrical moment $m d$.

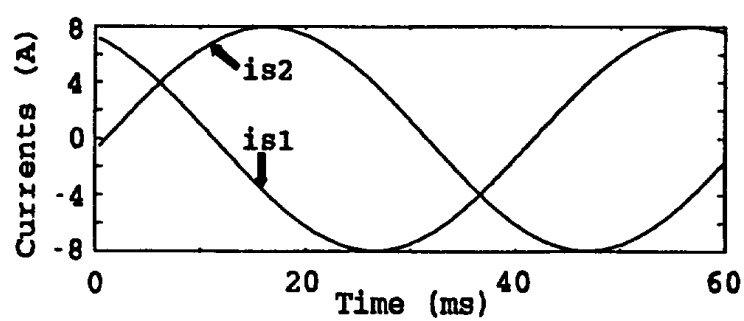

Fig. 13. The stator currents is $I$ and is 2 in stator coordinates.

On Figures 14 through 20 are shown the patterns of power, currents, voltages and moments, when the motor is controlled in a new manner and isd is varied.

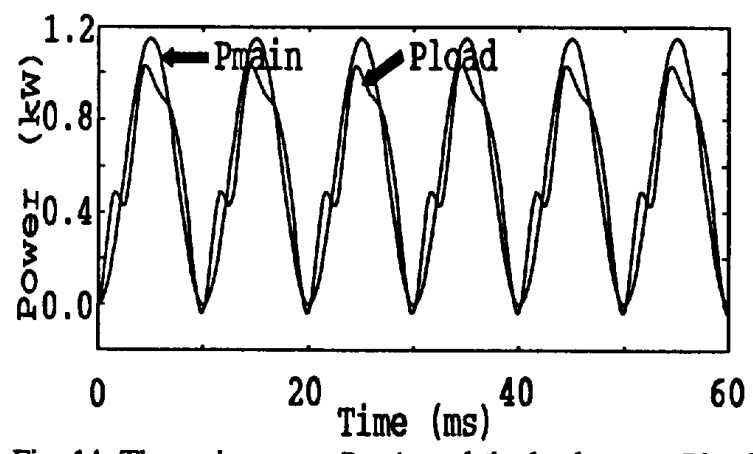

Fig. 14. The main power Pmain and the load power Pload. 


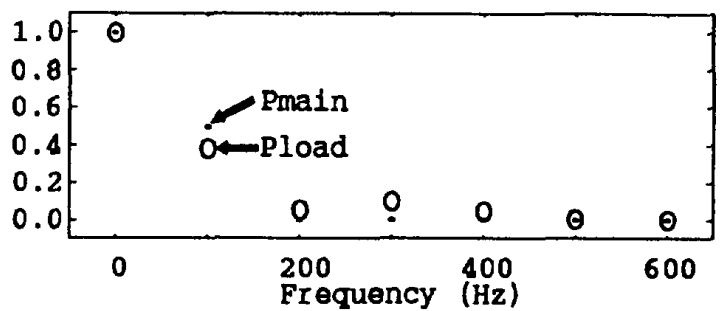

Fig. 15. The spectrum for the main power Pmain and the load power Pload.

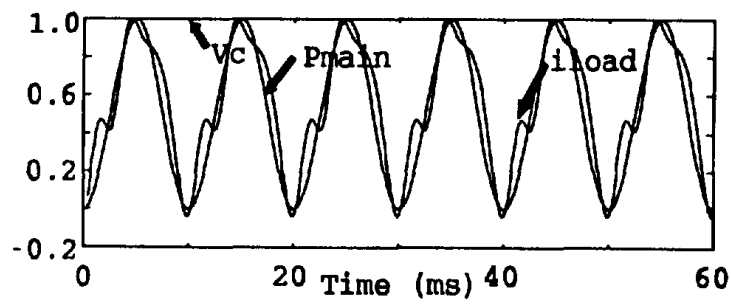

Fig. 16. The normalize value for the capacitor voltage $V c$ and the load current iload and the main power Pmain.

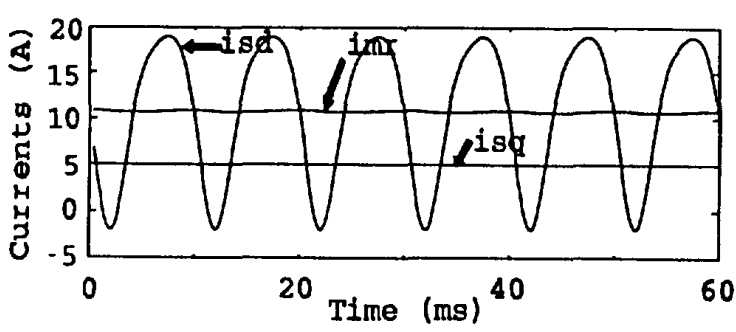

Fig. 17. The magnetization current $i m r$ and stator currents isd and $i s q$ in field vector coordinates.

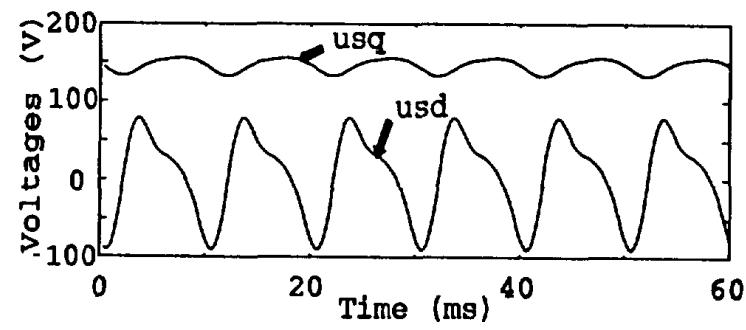

Fig. 18. The stator voltages $u s d$ and $u s q$ in field vector coordinates.

From Figures 14 to 16 it may be seen that Pload is nearly equal to Pmain, when the capacitor voltage is large as is the case for the boost converter.

\section{Reduction of the value of the capacitor $C$}

The power $P c$ and the energy $E c$ in the capacitor are

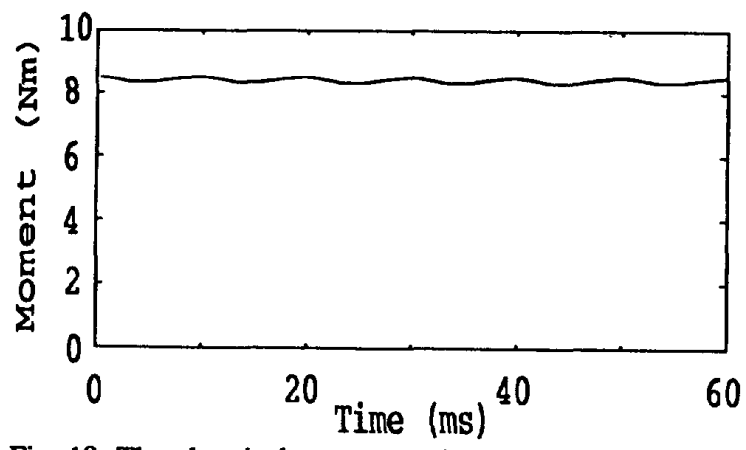

Fig. 19. The electrical moment $m d$.

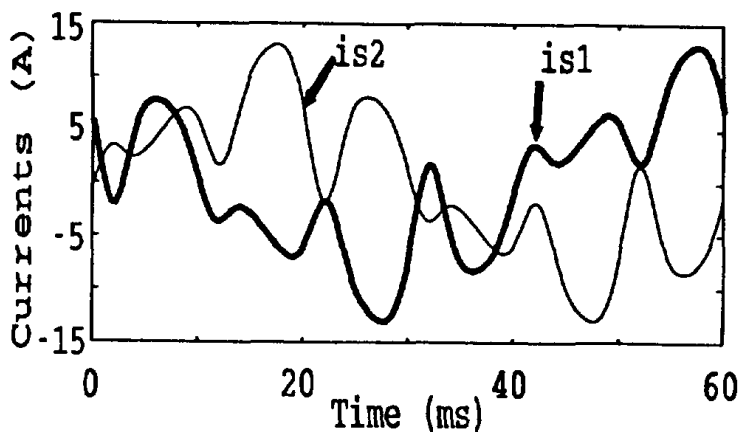

Fig. 20. $\mathrm{Th}_{1}$ ? stator currents is 1 and is 2 in stator coordinates.

computed at each sampling point and defined by:

$$
\begin{aligned}
& P_{c}(n)=2 / 3\left(P_{\text {main }}(n)-P_{\text {load }}(n)\right) \\
& E_{c}(n)=P_{c}(n) T=1 / 2 C\left(d V_{c}(n)\right)^{2} \\
& \quad=1 / 2 C\left(V_{c}(n)-V_{c}(n-1)\right)^{2}
\end{aligned}
$$

where $T$ is the sampling period and $t=n * T$.

The capacitor voltage and ripple in the capacitor voltage at the sampling point $t=n * T$ becomes:

$$
\begin{aligned}
& V_{c}(n)=V_{c \text {, ripple }}(n)+V_{c}(n-1)= \\
& \sqrt{\left(2 P_{c}(n) T\right) / C+V_{c}^{2}(n-1)} \\
& V_{c \text {,ripple }}(n)=V_{c}(n)-V_{c}(n-1)= \\
& \sqrt{\left(2 P_{c}(n) T\right) / C+V_{c}^{2}(n-1)}-V_{c}(n-1)
\end{aligned}
$$

In the Table I below may be seen how the ripple in the capacitor voltage changes as a function of control method and of capacitor value. The results in the table are taken from the simulations shown in Figures 7 through 20 .

The table shows that $C$ or $V c$,ripple can be reduced by 
Table I

The size of the capacitor and the ripple in the capacitor voltage.

\begin{tabular}{|c|c|c|c|c|}
\hline \multicolumn{2}{|c|}{ Normal method } & \multicolumn{2}{|c|}{ New method } & \multirow{2}{*}{$\frac{\text { Reduction }}{(\%)}$} \\
\hline$C\left(10^{-4}\right)$ & $V_{\text {csipm }}(V)$ & $\mathrm{C}\left(10^{-6} \mathrm{~F}\right)$ & $V_{\text {asife }}(V)$ & \\
\hline 1 & 1123 & 1 & 534 & 52 \\
\hline 3 & 555 & 3 & 230 & 59 \\
\hline 10 & 230 & 10 & 87 & 62 \\
\hline 100 & 30 & 100 & 10 & 67 \\
\hline 97 & 31 & 30 & 31 & 69 \\
\hline
\end{tabular}

several percent.

\section{Measurements on the inverter and the motor}

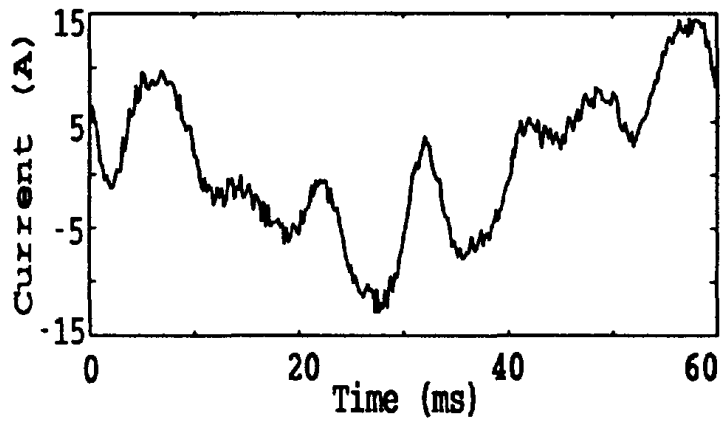

Fig. 21. The measurement value of the stator current is $I$ in stator coordinates.

All signal is passed through a 5 order FIR-lowpass filter with 256 taps. The filter has a cutoff frequency of $200 \mathrm{~Hz}$, and the PWM switching frequency is $20 \mathrm{kHz}$.

From Figure 21 it may be seen that the stator current isl look much like the simulated result in Figure 20.

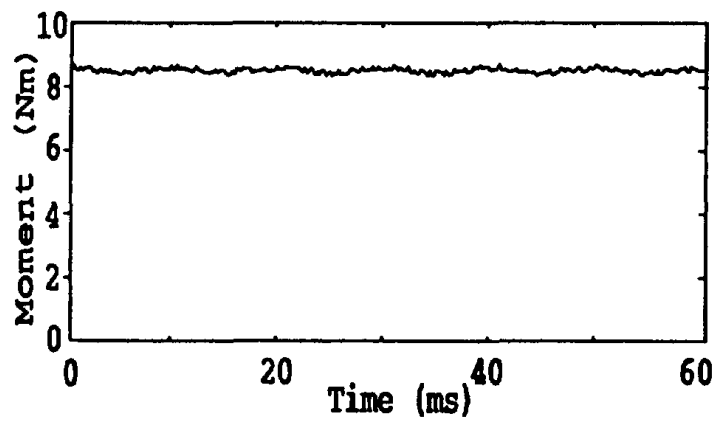

Fig. 22. The measurement value of electrical torque md.
The moment barely changes, even though the stator current is hardly sinusoidal with this method (See figure 22).

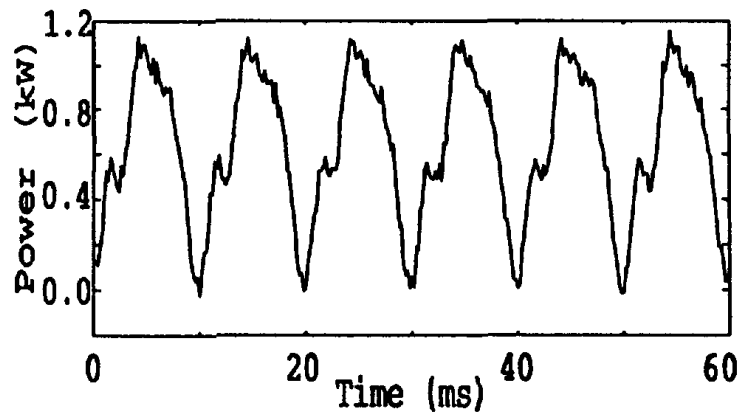

Fig. 23. The measurement value of the load power Pload.

The meausrement value of the load power Pload in Figure 23 is look like the simulated result in Figure 14.

\section{Conclusions}

It can be concluded that the measurements and the simulations give the same results. The new control principle will in some applications reduce the cost of the AC-DC converter concomitant with the converter absorbing a sinusoidal line current.

It is beneficial to design the motor especially for this control method. For example, it would be a good idea to design the stator for a larger current and a smaller voltage. This is due to the fact that the losses in the stator are increased by this method, whereas the losses in the rotor are unchanged. Furthermore, it is easier to control in such a way that Pload equals Pmain, when the capacitor voltage is greater than the $\mathrm{EMF}$ induced in the machine. 